\title{
A Visual Design Framework and Assessment to Inform Instruction
}

\author{
Sarah Huber \\ Purdue University, USA \\ Sivanand Puliyadi Ravi \\ Purdue University, USA
}

\begin{abstract}
As evidence of meeting program criteria required by the Accreditation Board for Engineering and Technology (ABET), engineering technology (ET) students are expected to both read and create graphical communications. Academic librarians' visual literacy (VL) instruction can support ET students' ability to communicate through graphics. Under comprehensive VL instruction, teaching visual design principles is an area of VL that supports graphical communication. An adaptive comparative judgment (ACJ) assessment was given to 115 ET students to inform visual design instruction and future research. A visual design framework supplemented the assessment to familiarize students with visual design principles. ACJ offers an alternative assessment model because instead of grading against a rubric of learning outcomes, it uses context to judge the quality of a work. The assessment results outline specific areas to focus visual design instruction for students to effectively navigate and create graphical communications.
\end{abstract}

Keywords: Visual literacy, assessment, visual design, adaptive comparative judgment, visual literacy instruction

\section{Introduction}

As evidence of meeting program criteria required by the Accreditation Board for Engineering and Technology (ABET), engineering technology (ET) students are expected to both read and create graphical communications. Graphical communication courses are not required by ABET, though, so instruction often falls on ET faculty even if they do not have the expertise or time to include it in their coursework (Keller et al., 2018). Academic librarians' visual literacy (VL) instruction can support students' ability to communicate through graphics. While graphical communication is a competency under VL according to library literature, practices under visual communication can support the reading and writing of graphics. Under a comprehensive $V L$ teaching plan, visual design principles are one of several approaches to teaching effective visual communication (Brown et al., 2016).

VL has different meanings and expectations depending on the context from which it is taught. Based on Kędra's review of VL definitions across different contexts (2018), Kędra and Žakevičiūtè offer three categories of VL skills: visual reading, visual writing, and other visual literacy skills.

Visual reading covers skills of image interpretation/analysis, evaluation, visual perception, knowledge of visual grammar and syntax and learned ability in visualverbal translation. Visual writing covers skills in visual creation, image production and use, and in effective visual communication. Other visual literacy skills include visual thinking and learning skills and applied use (such as using images ethically) (Kędra \& Žakevičiūtè, p. 2, 2019).

When teaching students skills for "effective and meaningful" visual communication, Brown et al. propose leading students through a process of inquiry. One question for students to ask themselves is, "What design strategies will I use?" (2016, pp. 65-66). As Malamed states, "Visual design affects the quality of learning, the value of the communication, and the motivation of the audience members. It leverages the brain's innate capabilities, improves engagement, and satisfies the audience's aesthetic sensibilities."

To inform visual design instruction, it is necessary to measure students' level of visual design competency within VL via assessment. As Kędra states, research on VL assessments is necessary to investigate questions in the field and demonstrate VL's value and importance in higher education curriculum (2018). 
This paper offers a VL assessment and framework to gauge prior knowledge in visual design to support visual communication instruction. The exploratory research presented is visual design as it applies to the reading and writing of data visualizations, but it can potentially apply across VL competencies.

At a university in the Midwest, $115 \mathrm{ET}$ students were presented with a visual design framework to orient them to how effective visual design helps viewers easily navigate graphical communications, specifically data visualizations. They were then asked to participate in a voluntary comparative judgment (CJ) assessment to gauge their visual design prior knowledge. The assessment offered pairings of data visualizations to compare and choose which they thought was the "best" and prompt students to explain their choice. The instruction team asked themselves, Do ET students choose data visualizations that reflect best practices in visual design? Based on observations from senior capstone projects and poster presentations, the team believed the students would choose visualizations not necessarily grounded in visual design but focused on the underlying data. In regards to the written portion, the team only wanted to see if any patterns emerged. The results showed a need to develop visual design instruction so students could make informed decisions when reading and creating graphical communications and to articulate meaningful feedback for their peers.

\section{Literature Review}

Studies show a divide between the demand students experience in higher education to navigate and create visual materials and the instructional support they receive to meet that demand (Hattwig et al., 2013). Faculty convey frustration with students' lack of skills to communicate effectively and persuasively with visual materials; they also express frustration with the support to offer that instruction (Green, 2006). When students self-report high levels of visual literacy skills and investigation into the topic shows otherwise (Brumberger, 2011), there is an increase in the divide between the demand to create visual communication and instructional support.

In response to the idea that millennials naturally possessed a high degree of $V L$ because of repeated exposure to technology, Brumberger administered a survey to help prove or disprove that belief. At the time, the term "digital native" was used to describe millennials, further enforcing the misconception. Four hundred eighty-five undergraduate students across a range of majors and program years at Virginia Tech University took the survey. The survey was designed to answer a number of questions about technology and proficiency, including how students rated their level of proficiency with presentation software such as Microsoft PowerPoint presentations. $75 \%$ of respondents reported being "somewhat or very skilled" in presentation software. The majority of students reported using templates that come with presentation software, and only $13 \%$ reported designing their own templates. Surprisingly, in an increasingly visual culture, only $49 \%$ incorporated images regularly, $40 \%$ said they sometimes did, and the remainder said they never incorporated images. While results showed the presence and use of visual information, including graphics, in students' lives, Brumberger concluded that "the data indicate clearly that the survey participants are far from adept at producing and interpreting visual communication" (Brumberger, 2011, p. 44).

ABET is the accrediting body for engineering and ET programs. ABET's 2020-2021 criteria for engineering students include "an ability to acquire and apply new knowledge as needed," "to communicate effectively," and "an ability to... analyze and interpret data" (ABET, 2020-2021). Whereas the criteria for ET includes "an ability to apply written, oral, and graphical communication in well-defined technical and non-technical environments; and an ability to identify and use appropriate technical literature" (ABET, 2020-2021). In 2000 , ABET responded to engineering employers' request that graduates enter the workforce with 21stcentury skills. Students had sufficient engineering skills, but lacked the ability to communicate. Like many educational organizations at the time, ABET thought student learning could be better assessed through curriculum outcomes. This led to the revamping of ABET's criteria for engineering programs. Criteria 3, "an ability to communicate effectively," is assessed through portfolio writing and competency tests. ABET did not require courses to meet this outcome but instead looked for evidence that this outcome was exercised across curriculum requirements. The argument is that if students experienced various environments in which communication takes place, they would be better prepared for how communication takes place in the workplace. Engineering faculty found it hard to integrate writing into their coursework, though. They argued it took time away from the core engineering curriculum, and they did not have the support needed, such as consultation time with experts, to effectively integrate writing communication into their classes (Williams, 
2001).

Graphical communication understanding and application are learning outcomes for ET students (ABET, 2020-2021). If engineering faculty find it hard to adequately integrate written communication into their curriculum, graphic communication beyond 3D modeling may be challenging. The curriculum for engineering and ET students typically emphasizes science, math, and engineering, but students take technology courses that implement applied practices. While engineering students study to develop new design solutions for complex problems, ET students study how to put those design solutions into practice within construction and manufacturing organizations (Michigan Technological Institute, n.d.). Graphic communication, as a subset of communication, is an essential skill in engineering because of the importance of conveying design ideas. Although not explicitly stated in the 2000 ABET criteria, it was implied that programs would include it under the ability to communicate effectively. In response to this outcome, a survey was conducted at the annual American Society of Engineering Educators (ASEE) in 2003 to rank the value of fourteen proposed graphic communication outcomes under the mandated $3(\mathrm{~g})$ criteria for effective communication. In engineering, graphic communications have included everything from manual drafting and pencil drawings to 3D computer drawing and simulation. In this survey, of the fourteen outcomes, "ability to create presentation graphics" is included. It states, "This outcome includes creating data graphs and charts, generating color raster images, and creating animations and slide show presentations." The results of the survey rank this outcome relatively low, third up from the bottom. Descriptive geometry and manual geometric construction techniques were the two lower, and the "ability to create 3D solid computer models was listed as the most important" (Barr, 2004, p. 5). The ABET criteria for engineering continue not explicitly to state graphic communication. As of 2016-2017, the ABET criteria for ET does under 3(f) "an ability to apply written, oral, and graphical communication in both technical and nontechnical environments; and an ability to identify and use appropriate technical literature" (ABET, 20162017)

A survey was administered to mechanical engineering (ME) faculty. When asked what visual materials faculty encourage students to use, 3D CAD solid models, graphs, charts and tables, diagrams and schematics, and sketches were the most popular. When asked how important visual literacy instruction was in the context of ME design, out of twenty-one faculty responses, fourteen considered it extremely important, six considered it somewhat important, and one considered it slightly important (Keller et al., 2018). While there is a lack of VL instruction to meet academic demands (Hattwig et al., 2013), there is also a lack of research on evaluating VL skills (Bowen, 2017; Kędra, 2018; Keller et al., 2018). Further, as Keller et al. (2018) argue, while literature is available on VL assessment, VL assessment within STEM is underrepresented. In response, at the ASEE 2018 conference, they proposed five benchmark standards a person in engineering design must meet to be considered visually literate. The standards include "Use design strategies and creativity to modify existing visual media and create original visual media" (p.7, 2018). Images located, adapted, and created in team-based senior capstone projects were assessed against the five standards. Students' capstone projects included documenting their design process and presenting their resulting design products.

To develop the five standards, the authors identified competency-based tools to assess VL skills in higher education, including Bowen's (2017) Visual Literacy Competency (VLC) rubric. The VLC rubric, intended to be both flexible and reliable, assesses competency levels specific to the identified important learning outcomes. The rubric includes the VL competencies analysis and evaluation, as well as the design and creation of visual text. The VLC rubric is built on the SOLO taxonomy, the Structured Object Learning Outcome Taxonomy, as it applies to VL skill competency (Bowen, 2017). Biggs and Collis' SOLO taxonomy identifies levels of learning by complexity. It begins with not knowing anything about a topic to being able to apply knowledge to unknown, future learning applications. It can be used to evaluate a learner's competency level (Biggs \& Collis, 1982). Lastly, the authors identified Arsland and Nalinci's (2014) use of a Likert scale to evaluate VL competencies. Applied in an interdisciplinary higher education context, the authors identified seven dimensions that a visually literate student should be able to practice. Students are assessed to see where on the scale their level of VL lies within the dimensions. Included is the dimension "Designing and creating visuals" (64). The Association of College and Research Libraries (ACRL) Competency Standards for Higher Education, American Association of School Librarians (AASL) Standards for the $21^{\text {st }}$ Century Learner, the enGauge $21^{\text {st }}$ Century Skills, among other standards, were used with the 
competency assessment tools to develop the five standards (Keller et al., 2018).

Huber et al. (2020) illustrates a collaboration between an ET librarian and ET faculty to support the VL demands for visual communications within ET. The partnership included VL instruction sessions and the adaptive comparative judgment (ACJ) software by RM Compare to assess student work. Students were required to make a visual map of their program work and a visual resume. For the assignments, there was instruction on visual resources to create visual material, ethical use of visual materials, and visual design principles to support their visual material creation. Huber's (2020) visual design framework, SHARC (Space, Hierarchy, Alignment, Repetition, Color), was included in the visual design instruction. After each submitted assignment, every student individually took the ACJ assessment. The assessment visually presented their peers' work side by side, two at a time. The student chose which she thought was "best" between the two and then, explain why. Each student received anonymous feedback from peers through this assessment process, and then turned in revisions of their work. The feedback that they received from their peers served as another opportunity for the students to learn, and the instructors were able to read and assess the students' feedback for evidence of VL skills. They also assessed the students' VL skills through the revised assignments. The researchers found that because ACJ is visual in nature, it served as a good tool to teach and assess visual material. Students made marked improvements on their revisions of the visual material, but their articulation of VL skills in the form of feedback was low, leaving an opportunity to further develop their instruction.

ACJ differs from traditional assessment tools where instructors use a rubric of learning outcomes to score against evidence of student work. ACJ comparatively presents two artifacts of work, and the judge chooses which is the better (Bartholomew, Zhang, Garcia Bravo, \& Strimel, 2019). ACJ is based on Thurstone's law of comparative judgment (CJ) principle introduced through a paper in 1927. Thurstone argued that humans work best with comparison when judging an object, whether it be an example of handwriting, values of a color, or ethical opinions. He proposed that it is difficult to judge something as a standalone piece, but given two objects side by side (A \& B), with a set of attributes to look for, we can judge whether A or B is the best example of those attributes. Once the judge decides which object is the better in comparison, she will be given a new set of comparisons ( $A$ \& $C$ ) depending on whether $A$ or $B$ was chosen. Comparison offers context. He showed that when you provide a group for comparisons, with each object being compared to another in the grouping (ranking order), a pattern emerges that is a mathematically reliable form of assessment while showing the relative quality of the individual works (Thurstone, 1927).

Pollitt and Murray brought $\mathrm{CJ}$ into current assessment practice through their use of $\mathrm{C} J$ with foreign language skills (1993). Pollitt then applied CJ in a design \& technology portfolio class. The portfolios consisted of diverse deliverables, including design details of prototypes created. CJ was the holistic approach needed to assess a product with different components. With a team of judges (instructors) having varied expertise, they took the CJ assessment. They chose between pairs of students' work and then gave feedback on their choices. Input from a range of expertise gave students valuable information that marking alone could not provide. Pollitt shared the material with a large group of judges at different locations, making CJ adaptable through scanning capabilities and information technology, hence ACJ (2004). Pollitt and his research team then created a web-based version through which people could take the ACJ assessment, as described in a later paper of their work (Kimbell et al., 2007). Any number of instructors can be invited to an ACJ assessment session. A single guiding statement helps instructors stay focused on what makes one example of a student's work a "better" choice over the other. ACJ "is a method for scoring students' work in which judges are asked only to consider validity while making their decisions; nevertheless, the result is extremely high reliability" (Pollitt, 2012, p. 27). Research has shown that the rate of reliability is higher when decisions are made comparing pairs of works, rather than subjective decisions based upon specific traits (Pollitt, 2004, 2012).

ACJ was originally intended for summative assessment and as a tool for teachers and professionals to use. In a university graphic design course, ACJ was used throughout the semester as a formative assessment tool, and students were engaged as judges (assessors). Limitations to formative group critique sessions led the research team to ask if students participating in ACJ sessions for assignments throughout the semester could lead to better designs and a greater understanding of visual design principles. The class was divided into two groups. One group took part in traditional group critique sessions. Designs were printed 
off from fellow groups (within the larger group) and given a conventional scoring rubric and a place for comments. Individualsreceived the rubric with feedback on their work. The other group participated in RM Compare's ACJ assessment sessions. The students in the ACJ sessions stated that they enjoyed the ACJ assessment more than traditional critique sessions, found it easier, and the feedback had more impact on their learning. Students tended to provide feedback with personal preferencesinstead of specific, desired traits. This tendency made it hard to identify what students learned. Additionally, students reported concern that peer feedback was not as good as instructor feedback. There was also frustration with how the RM Compare ranked work, which could lead to repeated comparisons. The study showed that students who participated in the ACJ feedback ranked lower in the quality of their work than their peers in the traditional critique groups at the beginning of the semester, but by the end of the semester, their rankings improved. This improvement, and the positive response from students participating, was evidence that ACJ positively impacted learning (Bartholomew et al., 2019).

This literature review conveys a need to support the graphical communication evidence ET students are expected to meet. There is a lack of research on VL assessments to inform visual communication instruction. Specifically, there is an even greater lack of VL assessments within STEM. While there are assessment tools, such as the VLC rubric and standards and the ACRL Visual Literacy Competency Standards for Higher Education, to score evidence of students' VL work, ACJ offers an alternative assessment model. ACJ engages instructors and students in the process of judgment and explanation through context. Additionally, ACJ allows a group of instructors and students to participate in the assessment so that students can benefit from a range of expertise in their feedback and gain exposure to peers' work.

\section{Methods}

The instruction team met in spring 2020 to plan a master's in engineering technology (MSET) research methods class. The instructors were an ET librarian and ET faculty member. The team agreed to emphasize the importance of visual materials in coursework by integrating VL instruction throughout the semester. Students would be required to communicate with visual materials in presentations and deliver a data visualization in their final project.

There was little evidence that students had received formal VL instruction in their program. The MSET faculty member asked that students receive substantial visual design instruction because data visualizations had been an area he perceived as needing improvement. Anecdotally, both instructors agreed that, through their observations of senior capstone projects and poster presentations, the main point of students' data visualizations was not always clear. It was common for students to spend more time explaining a visualization than an effective visualization should require. Additionally, students often used competing bright colors, limited their data graphs to bar and pie charts, and lacked clear visual paths for effective reading. This discussion led to the data visualization section topics:

1. identify the purpose of the visualization

2. identify the visualization message/story

3. choose the right graph for your data

4. apply visual design principles to create a visualization

The visual design section was broken down into three sections:

1. understand how visual design affects the navigation of data visualizations

2. apply visual design principles to navigate data visualizations

3. apply visual design principles to create navigable data visualizations

Because little evidence was available on how much, if any, VL instruction students had received in their master's program or undergraduate work, the team decided a prior knowledge assessment was necessary to inform instruction. As the university strongly emphasizes data literacy across programs, the instructors chose to assess students' visual design skills as it impacts the effectiveness of graphical communication (Brown et al., 2016; Malamed, 2015). The study builds on the Huber et al. (2020) VL instruction and assessment project described in the literature review. Specifically, the comparative assessment software, RM Compare from RM Results, was used in combination with Huber's (2020) visual design framework, SHARC (Space, Hierarchy, Alignment, Repetition, Color). 
RM Compare's assessment was a good fit because it visually compares two pieces of work, and comparative judgment software is used for students to assess each other and/or for instructors and professionals to evaluate student work. The model needed to be catered to the project because there was no student work to use with the software. The instructors met with RM Compare to see if they could experiment with the application. As noted in the literature review, one function of RM Compare's software is that, when students and/or instructors choose which comparison they think is "best," students' work is rated on a scale of lowest to highest. The team agreed they could provide 30 data visualizations for up to 200 students to compare two at a time. RM Compare was able to create an algorithm to make this work. As students took the assessment, the visualizations would be ranked "best" to "worst" based on which graphs students thought were the "best" examples of visual design.

The SHARC framework document by Huber (2020) was chosen as supplemental material to introduce students to visual design because it presents visual design principles and how they support the navigation of data visualizations, and includes examples of SHARC applied to data visualizations. Thirty visualizations were chosen by the instructors that were believed to be "good" and "bad" examples representing each component in SHARC. The data visualizations were found online from various resources. Visualizations included as "good" examples were chosen from people or organizations known for their work in visual design, such as Stephanie Evergreen's Evergreen Data blog. Images included as "bad" examples were found from Google searches using the keywords "bad" and "data visualizations" and "examples" or variations on those keywords. A few visualizations from Dear Data were included to represent hand-drawn examples. A rubric was created for the team to rate each visualization based on SHARC. See Appendix "Visual Design Rubric for Practice."

The instructors wanted to answer the research question, Do ET students choose data visualizations that reflect best practices in visual design? By allowing students to choose between visualizations, the instructors could gauge what ET students found to be good visual design examples in data visualizations. Once students chose the "best" work of two, , they were prompted to explain their choice. The students' choices in visualizations and the explanations given for their choices would inform the course VL instruction.

Close to 200 students from undergraduate and graduate ET programs were sent an email asking for their voluntary and anonymous participation in the assessment. They were informed that participation did not affect their grade in any way and that the assessment results would be used to develop future visual literacy instruction, specifically visual design instruction. The SHARC framework was sent as an attachment. The email also emphasized that students were only to compare the visual designs of the two visualizations and choose which they thought was "best." The comparisons were not the same data with different visualizations. The data was always different in each graph. Directions for signing into the assessment were given and they had a week to take the assessment at their convenience.

Once in the software, students saw the below directions at the top of the page (with a link to the SHARC framework was included in the directions). Figure 1 illustrates the comparison and page layout.

Directions: Click on 'A' or 'B' to choose which data visualization you think "best" represents effective visual design. You will then be prompted to explain your choice. *Note: Each data visualization uses a different dataset. Don't compare data; simply choose which design you think is better and explain why. Keep in mind the SHARC (space, hierarchy, repetition, color) framework to explain your choice. There are no wrong answers.

A hundred and fifteen students participated, sixteen of which were graduate students, and ninety-nine of which were undergraduates. The research team gathered valuable information from the choices students made and the language they used to articulate their choices in visualizations. A graduate statistical consultant provided statistical analysis of the data. 
Figure 1

RM Compare screen of two data visualizations

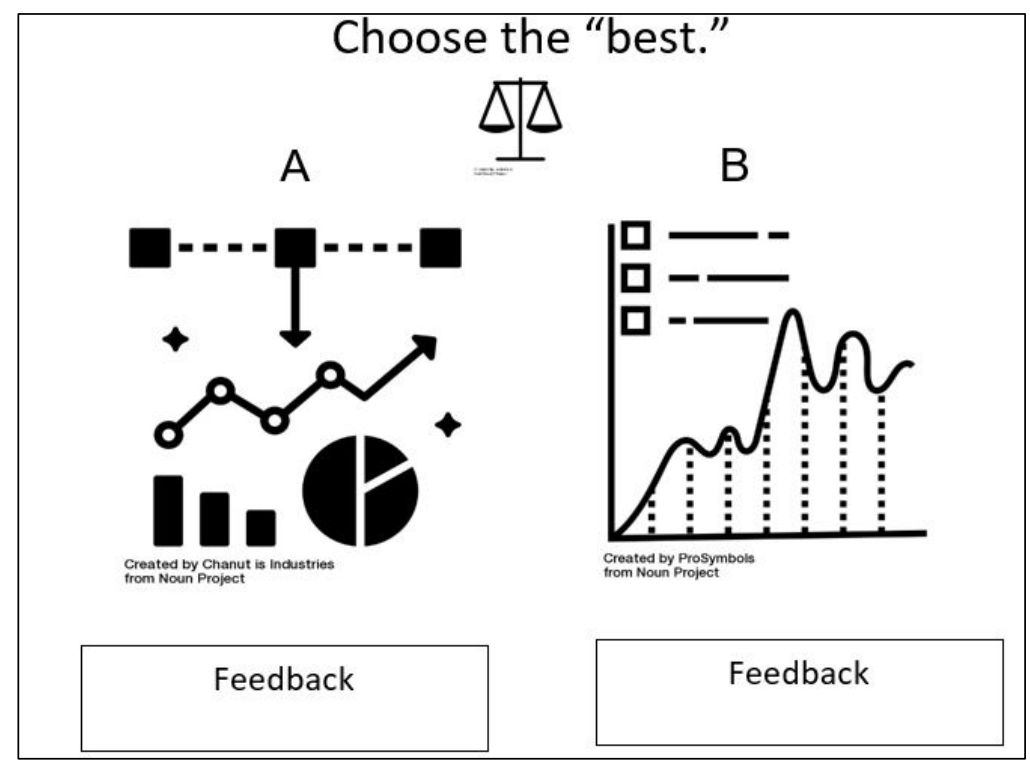

Results and Analysis

Figure 2 shows how the 30 images in the visual assessment ranked based on the students' choices. The graph on the far left, "Gender Pay Gap," was the highest-ranked choice, i.e., students chose this data visualization more often than any other data visualization as an example of the "best" visual design. The graph on the far right, "MLS Salaries per 8/1/2013," ranked it as the lowest, or "worst" example of visual design. The underlying statistical model used is the Bradley-Terry Model. This probability model assigns a positive real-valued score to a particular image 'i' compared to another image 'j.' $P(i>j)=P(i) /(P(i)+P(j)$ ). This algorithm iterates overall possible comparisons, maximizes the likelihood of the observed data, and finally converges to a unique solution (Agresti, 2013; "Bradley-Terry model," n.d.).

\section{Figure 2}

Relative rankings of the 30 data visualizations

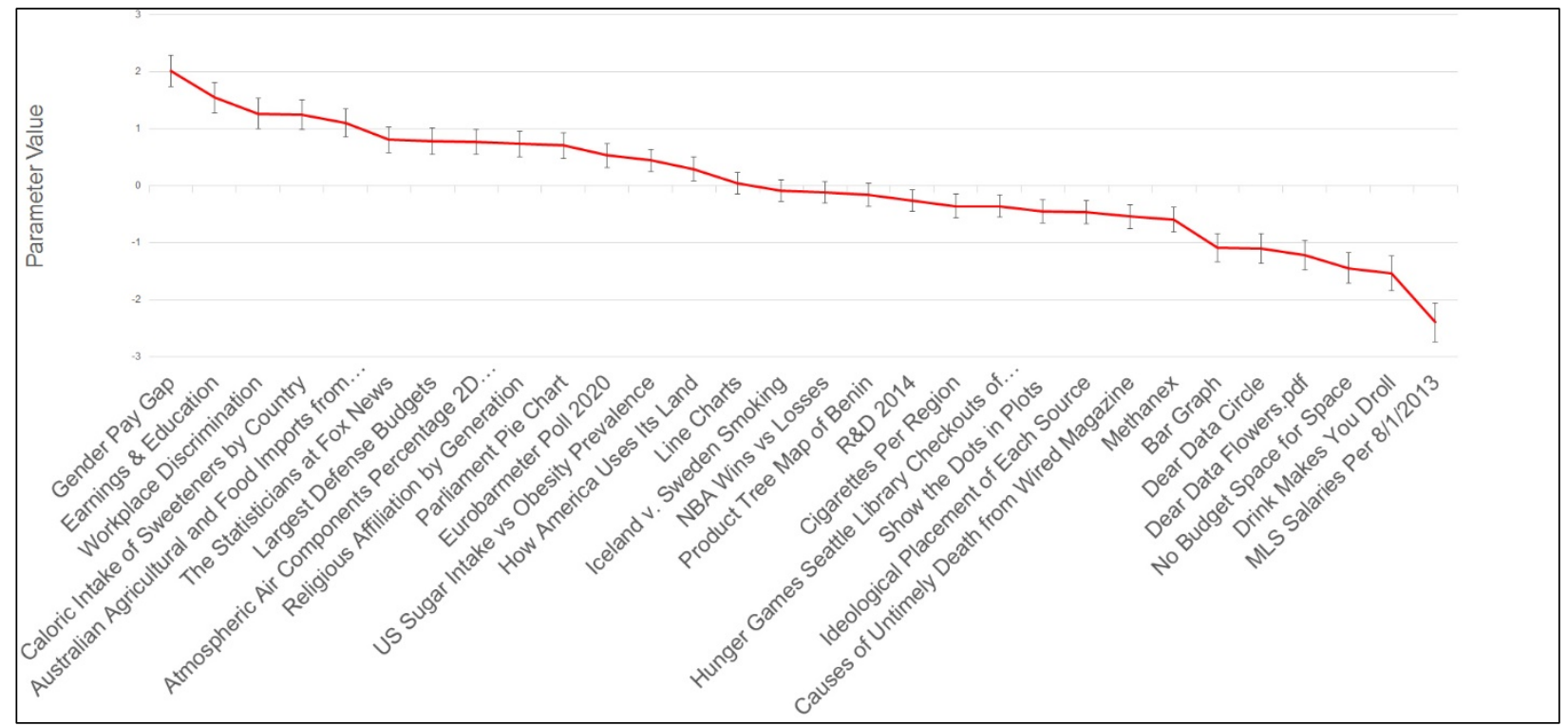


Figure 3 depicts the scores of each image by category in relation to students' ranking of images. Each data visualization was given a score, 1-4, using the Appendix, "Visual Design Rubric for Practice," created by the instructors. The rubric was based on the SHARC framework. The scores are on the Y-axis. The X-axis depicts the images lined up according to their final rank, based on students' choices of the "best" examples of visual design (left to right, highest-ranked to lowest-ranked).

\section{Figure 3}

Data visualization scores

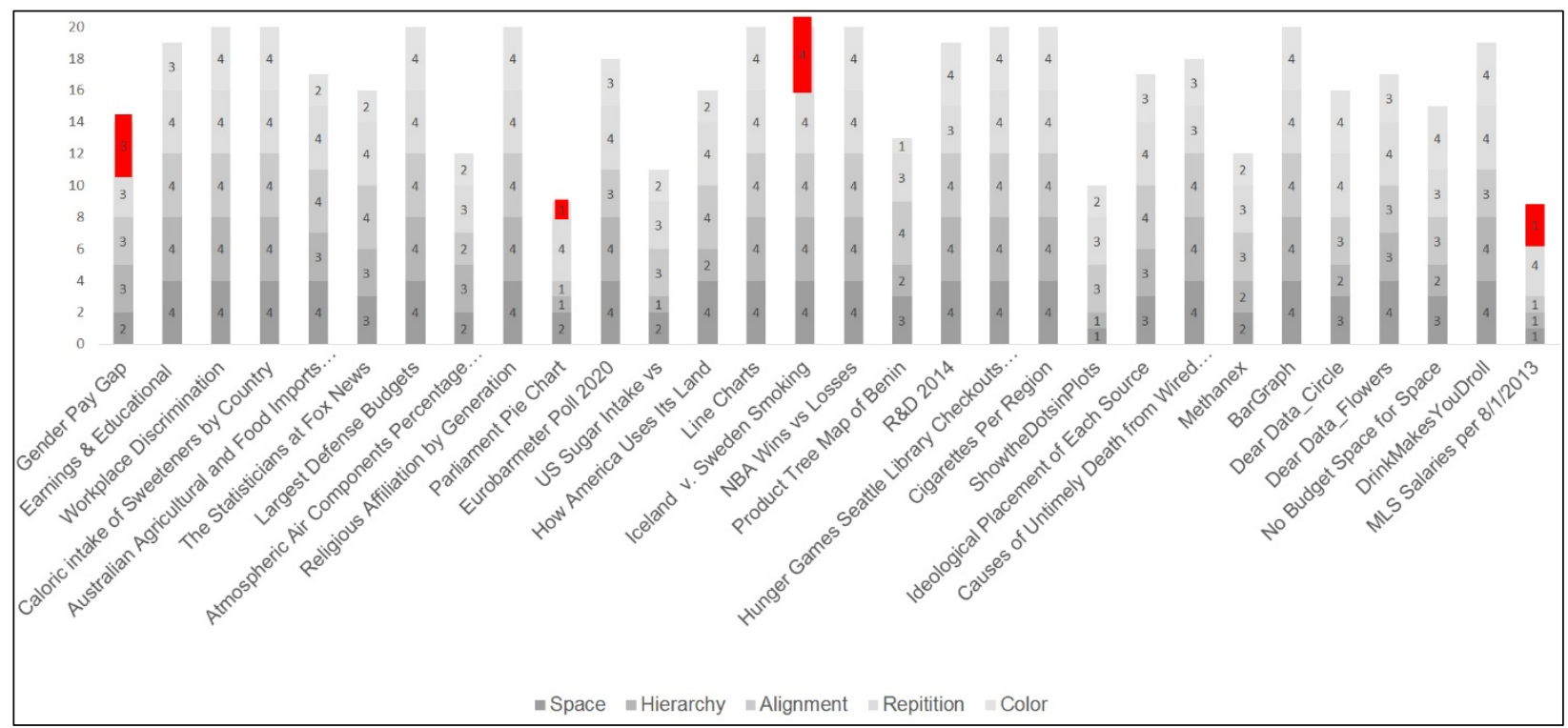

Students ranked the "Gender Pay Gap" visualization the "best" of all the visualizations, but the instructors only gave it a visual design score of 14 out of 20 . In terms of visual design, the space is cluttered with unnecessary competing elements. The viewer's eye can easily be drawn to visual detours. All elements, particularly space, could have been better utilized for the viewer to navigate the graph easily. The instructors and students agreed that the "MLS Salaries Pay Per 8/1/2013" was the "worst," with a score of 8 out of 20 given by the instructors and ranking last by the students. The only SHARC element that worked in the graph was Repetition, and one could say it was overused. Interestingly, The "Parliament Pie Chart" was given the second-lowest visual design score of 9 out of 20 by the instructors, particularly in regards to the lack of hierarchy and alignment, and the competing use of color, but the students ranked it in the upper half of "best." Lastly, a number of graphs the instructors thought were excellent examples of visual design did not match the students' rankings, which were in the middle or low end of the scale. For example, with "Iceland v.Smoking," the use of SHARC elements creates a clear navigational path for viewers to read and comprehend the graphical communication.

Although there are graphs the students and instructors agreed on, these findings may indicate students focused more on the underlying data than the visual design. If the comparisons had been based on the same data, maybe students would have made different decisions, but the software was not set up to work that way. The advantage to comparing graphs representing different data may be that it forces the assessor to focus only on the design. The results of the assessment indicate a need for two-part instruction: 1) a session that focuses on identifying the right graph for the data; and 2) a session on visual design principles to create easy-to-navigate graphical communications.

The instructor's scores are not set in stone and there is room to debate the effectiveness of different design elements. Instruction and time for classroom discussion would encourage debate, which might make students more informed andpurposeful in their, visual design decisions, even if others would make different decisions. 
Table 1 reveals a significant difference in ratings for the categories of hierarchy and alignment from the top five "best" and the bottom five "worst" visualizations the students chose. This difference indicates that these factors played a greater role in students' choices over the other SHARC elements. As stated above, the "Parliament Pie Chart" was given one of the lowest visual design scores by the instructors, particularly in regards to hierarchy and alignment, but the students ranked it in the upper half "best." Further investigation, through instruction time, could help inform the influence these elements had on students' choices.

\section{Table 1}

Comparison of "Best" and "Worst" ranked data visualizations.

\begin{tabular}{|c|c|c|c|c|c|c|c|}
\hline \multicolumn{3}{|c|}{ Data Visualization Ranking } & \multicolumn{5}{|c|}{ Avg. Rating } \\
\hline & Ral & & Space & Hierarchy & Alignment & Repetition & Color \\
\hline Top 5 & 1 & 5 & 3.6 & 3.6 & 3.8 & 3.8 & 3.2 \\
\hline Bottom 5 & 26 & 30 & 3.4 & 2.6 & 3.2 & 3.8 & 3.4 \\
\hline \multicolumn{3}{|l|}{ Difference } & 0.2 & 1 & 0.6 & 0 & -0.2 \\
\hline \multicolumn{3}{|c|}{ Correlation between rank and scores } & -0.03 & -0.20 & -0.04 & -0.11 & 0.11 \\
\hline
\end{tabular}

Figure 4 illustrates the variability in choices among students. Students above the red line indicate those whose choices deviate from the rest. It could be interpreted that students were inconsistent in their choices. However, most students are below the red line. This variability is expected and can be treated as noise. Overall, there are a few outliers, which can be read as the students having similar prior knowledge of visual design.

\section{Figure 4}

Judge Misfits

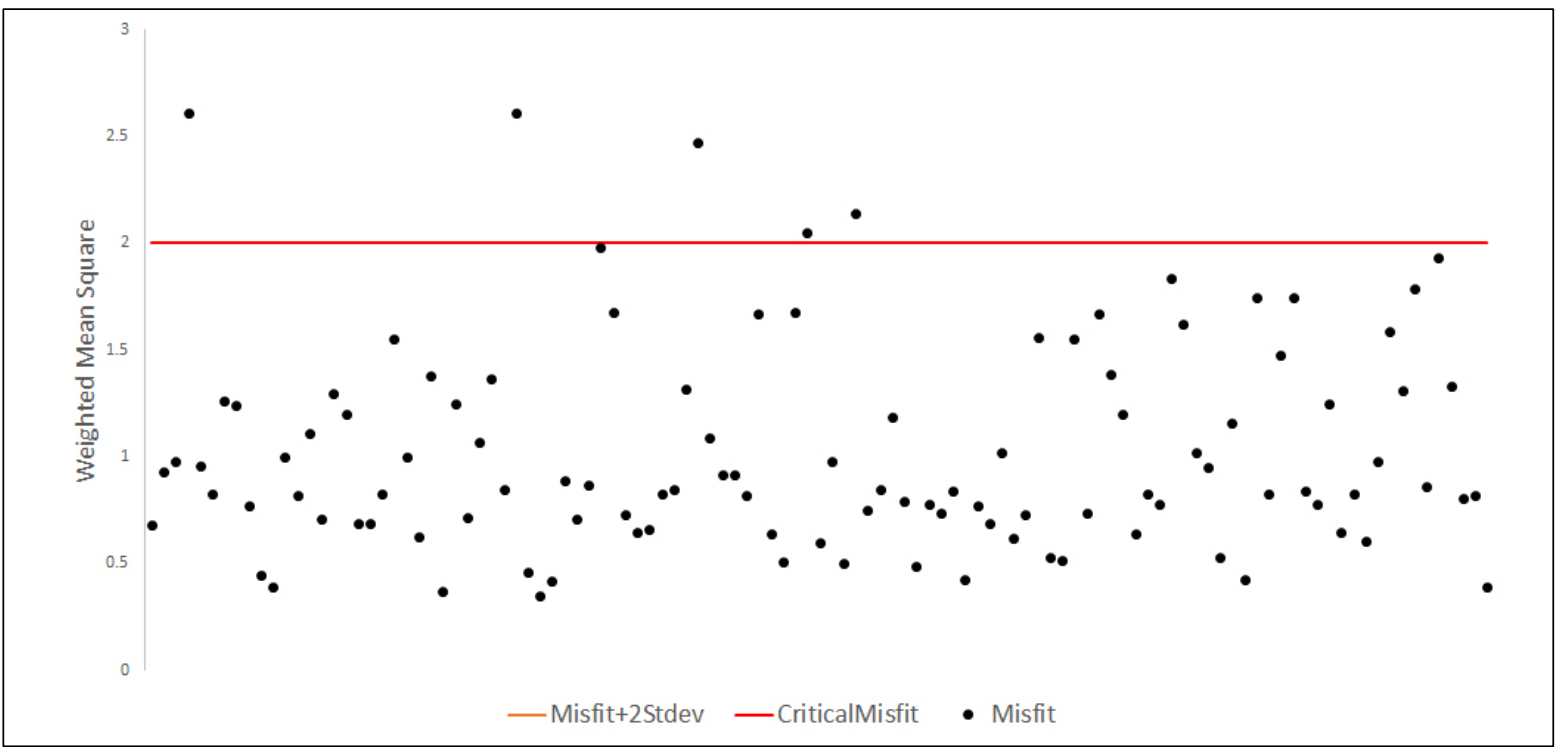

Note. The mean square can only be positive; that is why we do not see any values below zero.

The Figure 5 word cloud shows the words students used in their explanations for the choices they made. "Data," "color," and "colors" were used the most. Words such as "easy," "understand," "hard," "read," "information" also rank high in usage. Randomly sampled examples of students' explanations include:

1. "The color block is more attractive. Space and the hierarchy are better incorporated in A."

2. "A is more concise yet informative."

3. "B is easier to understand the data trend."

4. "I cannot focus on the data in A because of the background." 
5. "Too much going on in ' $\mathrm{B}$ '”

6. "The spacing fits the data, and the color pallet also makes sense for the data."

7. "The data is described in a reasonable fashion. The colors and spacing make sense for the described data, and the labeling makes it clear to the observer what they are looking at."

8. "This one has better hierarchy and alignment design. It repeats its data in columns, and as the columns rise in size, they move to the right. The other design has its data point chaotically organized to fit in a square, which leads to confusion."

9. "A uses too many colors to overcomplicate while B only uses four distinct colors as well as has it simplified with few words and symbols."

10. "A has more color and hierarchy, but B has more space and repetition. B is more simplified and, therefore, easier to read and understand. However, A is not overly complicated as well and also has a flower image that can be left as an imprint in people's mind when they see it."

11. "I like chart graphs more than drawings."

\section{Figure 5}

Word Cloud

aligned (17) alignment (25) although (14) appealing (19) axis (12) background (17) bar (26) bars (15) $_{\text {better }}$ (94) bolded (13) categories (12) chart ${ }_{(50) \text { charts (15) }}$ chose (12) clean (20) Clear (69) clearer (12) clearly (26) cluttered (21) color $_{(124)}$ colors

(108) compare (14) compared (17) comparison (18) complicated (12) comprehend (14) Confusing (31) contrast (17) countries (21) ${ }_{\text {country (11) }} \mathbf{a} \boldsymbol{\alpha} \boldsymbol{a}_{(236)}$ design ${ }_{(39)}$ different $_{(42) \text { difficult (18) }}$ displayed (14) due (14) $\mathrm{e}$ a jer (119) easily (20) $\mathrm{e}$. S. eventy (16) eye (15) $_{\text {follow }}{ }_{(30)}$ font (17) forward (12) going ${ }_{(27)}$ graph ${ }_{(157)}$ graphic $_{(28)}$ graphs $_{(32)}$ hard $_{(36)}$ hierarchy (43) important (16) information looking (12) LOKS (53) lot (16) nice (16) numbers (28) option (34) organized (24) percentages (17) pie (25) point (13) points (14) present (12)

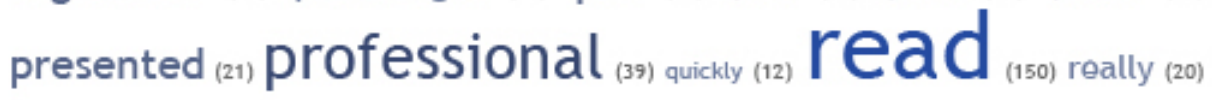
repetition ${ }_{(28)}$ representation (16) seems (17) sense (23) showing (11) shows (25) similarly (16) $_{\text {simple }}$ (50) size (15) $_{\text {SpaCe }}$ (63) spaced (15) $_{\text {spacing (36) }}$ straight (15) takes (13) text (14) think (16) title (23) together (11) understand ${ }_{(155)}$ used $_{(24)}$ uses $_{(17)}$ visual $_{(59)}$ visually (34) words (13)

In addition, Table 1 indicates that hierarchy and alignment informed students' decisions. Their word choices 
show they used those words in their explanations, but they are not the top words. Since "data" and "color" are the most used words, there may be a disconnect between what they chose and their ability to articulate their choices. Additionally, although the examples are a small percentage of the explanations captured and randomly chosen, they represent a lack of detail and understanding of specific words, such as hierarchy and space. There may also be an inability ,to articulate how the different visual design elements work together to support visual communication. The last two comments, 10 and 11, refer to hand drawings of graphs the instructors included. The graphs could be considered more artistic than scientific, but the instructors believed they employed effective visual design principles. The hand-drawn graphs ranked low on the scale of student choices. Again, this may indicate a focus on data over design.

\section{Discussion}

This paper offers an ACJ assessment tool combined with a visual design framework to assess ET students' visual design prior knowledge. An exploratory study, the results give valuable information for future teaching and research. The instructors believe students were reading and creating graphical communication with limited knowledge of visual design based on observations of student capstone projects and poster presentations. Between the choices made and the explanations given, the instructors believe students were more focused on the data and could benefit from visual design instruction as part of a larger VL instruction series. Specifically, students were drawn to bar and pie charts and primary color use in the visualizations. The study demonstrated a divide between what the instructors found to be good examples of visual design and what the students thought were good design examples. Lastly, while students appeared to rely on hierarchy and alignment in their decision-making, they were not words ranked the highest in the explanations. Overall, the explanations given lacked the details to suggest an understanding of the effect visual design principles have on the navigation of data visualizations. Further, as a group, students made similar choices, suggesting they share similar visual design beliefs.

There were limitations in that it is possible students would have chosen differently if they were given comparisons of the same data. It is also possible that the way the assessment was designed more accurately revealed students' prior knowledge of visual design. Additionally, just as the assessment was about to be given to students, the Covid-19 pandemic happened. The ET librarian was going to visit theclasses that were taking the assessment to explain the SHARC framework, how the assessment worked, and its purpose. Instead, an email included as much detail as possible without overwhelming students. Additionally, more students may have taken the assessment without the pressures that immediately hit campus because of the pandemic. Lastly, the instructors would have preferred a follow-up conversation with students about the survey, but the circumstances made it too difficult. Future work will include further developing the SHARC framework, using ACJ for prior knowledge, formative and summative assessments, and hosting focus groups to learn about students' experience using these two tools.

This assessment and framework combination is significant because it responds to Kędra's call for more research on VL assessments to answer questions in the field and to support the value of VL instruction in higher education. Although exploratory, it offers an alternative assessment model that uses context to judge quality over scoring against a rubric or set of standards or competencies. This study used SHARC, but standards or competencies could be integrated instead.

RM Compare's software is ideal, but not all libraries have the funding to purchase it. The strength of an ACJ assessment is to use it for both formative and summative assessments, and as this study showed, prior knowledge assessments. Some practical, low-cost options to integrate the idea of comparative judgment is to create a Google slide deck or something similar, where pieces of work are placed side by side. Within the comments section, each assessor can say which they think is "best" and explain why. This option does not rank the choices and change the comparisons based on ranking, but it is a start to judging in context. Another idea is to photocopy student work and make zines or booklets. Each page opening is a comparison and fun way to present student work. Letters can be at the top of each page (A \& B). Students can have a form where they list which examples they think are "best" in the comparisons and explain why. Ideally, in both examples, students submit electronic documents for their explanations so that text analysis can be done through a simple word cloud or through more detailed analysis options, such as Voyant or RapidMiner. 


\section{Conclusion}

ET students need VL support to make informed decisions about reading and creating graphical communications, as well as giving feedback to their peers. Although graphical communication may be seen as the domain of graphic designers, there is no evidence in the literature that engineering and ET students receive instruction from them. VL instruction from academic librarians that includes visual communication instruction can help ET students successfully navigate graphical communication. Specifically, visual design instructionis a way to engage students with what makes graphical communication effective and ineffective. The work presented is intended to foster discussion and future work. As stated previously, it is ideal that visual design instruction includes conversations and debates about visual design principles. It is not the intention of this paper to present prescriptive material but rather materials to work with and explore dynamic instruction in the classroom and future research. From past instruction with students, they enjoy this topic. They experience the pressure to communicate through visuals, but a one-stop-shop to help them create effective and meaningful visual communication is not available. When asked where they learn how to create visuals, piecemeal stories emerge with gaping holes. Standing in front of the classroom with a list of standards or competencies out of context can be hard to deliver with lasting impact. ACJ with SHARC can be a start to more actively engage students with the assessment process to better support VL and demonstrate its value in higher education.

\section{References}

Association of College \& Research Libraries. (2011, October). ACRL Visual Literacy Competency Standards for Higher Education, Association of College \& Research Libraries (ACRL). Retrieved November 23, 2020, from http://www.ala.org/acrl/standards/visualliteracy

Accreditation Board for Engineering and Technology (ABET). (2016-2017). Criteria for Accrediting Engineering Technology Programs, 2016 - 2017| ABET. https://www.abet.org/accreditation/accreditation-criteria/criteria-for-accrediting-engineeringtechnology-programs-2016-2017/\#1

ABET. (2020-2021). Criteria for accrediting engineering programs, 2020-2021 | ABET. https://www.abet.org/accreditation/accreditation-criteria/criteria-for-accrediting-engineeringprograms-2020-2021/

ABET. (2020-2021). Criteria for accrediting engineering technology programs, 2020 - 2021. Retrieved https://www.abet.org/accreditation/accreditation-criteria/criteria-for-accrediting-engineeringtechnology-programs-2020-2021/

Agresti, A. (2013). Categorical data analysis (3rd ed., V). Somerset: Wiley. https://ebookcentral.proquest.com/lib/purdue/detail.action?doclD=1168529\&pq-origsite=primo

Barr, R. E. (2004). The current status of graphical communication in engineering education. In Proceedings - Frontiers in Education Conference, FIE (Vol. 3, p. S1D/8-S1D13). https://doi.org/10.1109/fie.2004.1408688

Bartholomew, S. R., Zhang, L., Garcia Bravo, E., \& Strimel, G. J. (2019). A Tool for formativeassessment and learning in a graphics design course: Adaptive comparative judgement. The Design Journal, 22(1), 73-95. https://doi.org/10.1080/14606925.2018.1560876

Bowen, T. (2017). Assessing visual literacy: A Case study of developing a rubric for identifying and applying criteria to undergraduate student learning. Teaching in Higher Education, 22(6), 705719. https://doi.org/10.1080/13562517.2017.1289507

Bradley-Terry model - Wikipedia. (n.d.). Retrieved November 29, 2020, from https://en.wikipedia.org/wiki/Bradley-Terry model 
Brown, Nicole E, Bussert, Kaila, Hattwig, Denise, \& Medaille, Ann. (2016). Visual literacy for libraries: A practical, standards-based guide. EScholarship, UC Berkley.

https://escholarship.org/uc/item/5210p2nx

Brumberger, E. (2011). Visual literacy and the digital Native: An Examination of the millennial learner. Journal of Visual Literacy, 30(1), 19-47. https://doi.org/10.1080/23796529.2011.11674683

Biggs, J. B., \& Collis K. F. (1982). Evaluating the quality of learning: The SOLO taxonomy (Structure of the Observed Learning Outcome). Academic Press.

Green, D. (2006). Using digital images in teaching and learning: Perspectives from liberal arts institutions. Retrieved November 22, 2020, from https://academiccommons.org/using-digitalimages-in-teaching-and-learning-perspectives-from-liberal-arts-institutions/

Hattwig, D., Bussert, K., Medaille, A., \& Burgess, J. (2013). Visual literacy standards in higher education: New opportunities for libraries and student learning. Portal, 13(1), 61-89. https://doi.org/10.1353/pla.2013.0008

Huber, S. (2020). SHARC: A Visual design framework. Libraries faculty and staff creative materials. https://docs.lib.purdue.edu/lib fscm/32

Kędra, J. (2018). What does it mean to be visually literate? Examination of visual literacy definitions in a context of higher education. Journal of Visual Literacy, 37(2), 67-84. https://doi.org/10.1080/1051144x.2018.1492234

Kędra, J., \& Žakevičiūtè, R. (2019). Visual literacy practices in higher education: What, why and how? Journal of Visual Literacy, 38(1-2), 1-7. https://doi.org/10.1080/1051144x.2019.1580438

Keller, C., Robinson, L., \& Ault, H. (2018). Board 82: Visual literacy in mechanical engineering design: A Practical approach to assessment and methods to enhance instruction. In 2018 ASEE Annual Conference \& Exposition Proceedings. ASEE Conferences. https://doi.org/10.18260/1-2--30117

Kimbell, R., Wheeler, T., Miller, S., \& Pollitt, A. (2007). E-scape portfolio assessment - phase 2 report. London: Technology Education Research Unit, Goldsmiths, UL. https://assets.publishing.service.gov.uk/government/uploads/system/uploads/attachment data/file 1606018/0107 RichardKimball et al e-scape2report.pdf

Malamed, C. (2015). Like a hand in glove. In Visual Design Solutions (pp. 3-10). Hoboken, NJ, USA: John Wiley \& Sons, Inc. https://doi.org/10.1002/9781119153801.ch1

Michigan Technological Institute. (n.d.). Engineering vs. engineering. Retrieved November 17, 2020, from https://www.mtu.edu/admissions/programs/majors/differences/

Pollitt, A. (2004). (PDF) Let's stop marking exams. Retrieved November 25, 2020, from https://www.researchgate.net/publication/241197532 Let's stop marking exams

Pollitt, A. (2012). The method of adaptive comparative judgement. Assessment in Education: Principles, Policy \& Practice, 19(3), 281-300. https://doi.org/10.1080/0969594X.2012.665354

University, W. S. (n.d.). What is engineering technology? Retrieved November 17, 2020, from https://engineering.wayne.edu/et/about/what-is-et.php

Williams, J. M. (2001). Transformations in technical communication pedagogy: Engineering, writing, and the ABET engineering criteria. Technical Communication Quarterly, 10(2), 149-167. https://doi.org/10.1207/s15427625tcq1002_3 


\section{Acknowledgements:}

Special thanks to Dr. Duane Dunlap, Purdue University, for the visual literacy instruction planning sessions and tremendous support in developing the ACJ assessment. Thank you, Dr. Frederick Berry, Purdue University, for the support you gave in administering the survey to your classes.

\section{Visual Design Rubric for Practice of Skills}

\section{Appendix}

\begin{tabular}{|c|c|c|c|c|}
\hline Category & Advanced (4) & Proficient (3) & Developing (2) & Beginning (1) \\
\hline Space & $\begin{array}{l}\text { Practices } \\
\text { intentional use of } \\
\text { and } \\
\text { arrangement } \\
\text { of elements to } \\
\text { create visual } \\
\text { harmony }\end{array}$ & $\begin{array}{l}\text { Demonstrates } \\
\text { limited skills for } \\
\text { the intentional } \\
\text { use of and } \\
\text { arrangement of } \\
\text { elements to } \\
\text { create visual } \\
\text { harmony }\end{array}$ & $\begin{array}{l}\text { Includes } \\
\text { elements to } \\
\text { create visual } \\
\text { balance }\end{array}$ & $\begin{array}{l}\text { Displays limited } \\
\text { to no skills on } \\
\text { the use of } \\
\text { space }\end{array}$ \\
\hline Hierarchy & $\begin{array}{l}\text { Practices hierarchy } \\
\text { prioritizes } \\
\text { elements from the } \\
\text { most important } \\
\text { and supporting } \\
\text { details }\end{array}$ & $\begin{array}{l}\text { Demonstrates } \\
\text { limited skills on the } \\
\text { hierarchy to } \\
\text { prioritize elements } \\
\text { from most important } \\
\text { to supporting details }\end{array}$ & $\begin{array}{l}\text { Demonstrates } \\
\text { hierarchy to } \\
\text { prioritize } \\
\text { elements }\end{array}$ & $\begin{array}{l}\text { Displays limited to } \\
\text { no skills on the } \\
\text { use of hierarchy }\end{array}$ \\
\hline Alignment & $\begin{array}{l}\text { Practices grouping } \\
\text { elements with } \\
\text { seen or unseen } \\
\text { lines to keep } \\
\text { information } \\
\text { organized }\end{array}$ & $\begin{array}{l}\text { Demonstrates } \\
\text { limited skills on how } \\
\text { to group elements } \\
\text { with seen or unseen } \\
\text { lines to keep } \\
\text { information } \\
\text { organized }\end{array}$ & $\begin{array}{l}\text { Demonstrates } \\
\text { skills on how to } \\
\text { use alignment to } \\
\text { organize } \\
\text { information }\end{array}$ & $\begin{array}{l}\text { Displays limited to } \\
\text { no skills on the } \\
\text { use of alignment }\end{array}$ \\
\hline Repetition & $\begin{array}{l}\text { Practices unifying } \\
\text { elements so } \\
\text { important } \\
\text { differences } \\
\text { became a focus } \\
\text { point }\end{array}$ & $\begin{array}{l}\text { Demonstrates } \\
\text { limited skills on how } \\
\text { to unify elements, } \\
\text { so important } \\
\text { differences became } \\
\text { a focus point }\end{array}$ & $\begin{array}{l}\text { Demonstrates } \\
\text { skills on how to } \\
\text { use repetition to } \\
\text { create focus } \\
\text { points }\end{array}$ & $\begin{array}{l}\text { Displays limited to } \\
\text { no skills on the } \\
\text { use of repetition }\end{array}$ \\
\hline Color & $\begin{array}{l}\text { Practices the use } \\
\text { of color to create } \\
\text { mood and } \\
\text { emphasis }\end{array}$ & $\begin{array}{l}\text { Demonstrates } \\
\text { limited skills on how } \\
\text { to use color for } \\
\text { mood and emphasis }\end{array}$ & $\begin{array}{l}\text { Demonstrates } \\
\text { skills on how to } \\
\text { use color to } \\
\text { create an effect }\end{array}$ & $\begin{array}{l}\text { Demonstrates } \\
\text { little to no skills } \\
\text { on how to use } \\
\text { color to create an } \\
\text { effect }\end{array}$ \\
\hline
\end{tabular}

\section{APA citation format $\left(7^{\text {th }}\right.$ edition) for this publication:}

Huber, S. \& Ravi, S. P. (2021). A Visual Design Framework and Assessment to Inform Instruction. In J. Lee, S. M. Christensen, S. Beene, X. Chen, and W. Huang (Eds.), Visual literacy in the virtual realm: The book of selected readings 2021 (pp. 39-52). International Visual Literacy Association. https://doi.org/10.52917/ivlatbsr.2021.015 